1. Doyle JR (1999). Extensor tendons acute injuries. In: Green DP, Hotchkiss R, Pederson WC eds Greeen's operative hand surgery. 4th ed. Philadelphia: Churchill Livingstone;1441-1462.

2. Miller H (1942). Repair of severed tendons of the hand and wrist. Surg Gynecol Obstet; $75: 693-698$.

3. Eaton RG (1969). The extensor mechanism of the fingers. Bull Hosp Joint Dis; 30 :39-47.

4. Dominic Patillo et al (2012). Open extensor tendon injuries: an epidemiologic study. Hand Surg;17(1):37-42.
5. Mohammed Ahmed Kadah (2015). Evaluation of the results of management of acute extensor tendon injuries of the hand. Menoufia Medical Journal;28(1):149-153.

6. Newport ML et al (1990). Long term results of extensor tendon repair. J Hand Surg; 15A, 961-966.

7. Khachaba YA (2008). Evaluation of the outcome after repair of injuries to the extensor tendons of the hand, [MScs thesis]. Cairo: Cairo University; 90-133.

8. Fitoussi $\mathbf{F}$ at al (2007). Extensor tendon injuries in children. J Pediatr Orthoop; 27: 863-866.

\title{
ĐĂC ĐIỂM LÂM SÀNG, CÂN LÂM SÀNG VÀ HİNH ẢNH CộNG HƯỞNG TỪ Ở BÊNNH NHÂN TĂNG SINH LÀNH TÍNHTUYẾN TIỀN LIÊTT ĐƯợC CAN THIỆP NÚT ĐộNG MẠCH TUYẾN TIỀN LIỆT
}

\section{TÓM TĂT}

Mục tiêu: Mô tả đặc điểm lâm sàng, cận lâm sàng và hình ảnh cộng hưởing từ của bệnh nhân tăng sinh lành tính tuyến tiền liêt được can thiêp nút đônng mach tuyến tiền liệt. Đối tượng và phương pháp:Nghiên cứu hồi cứu được thươ hiển trên $66 \mathrm{BN}$ tăng sinh lành tính tiền liệt tuyến tuyến được can thiệp nút động mạch tuyến tiên liệt tại BV Hữu Nghị từ 05/2015 đến 06/2019, mô tả đặc điểm lâm sàng, cận lâm sàng và hình ảnh công hưởng từ trước can thiệ. Kết quả: Từ tháng 05/2015 đến tháng 06/2019, có 66 BN với tuổi trung bình $73,58 \pm 7,9$ tuổi,thể tích trung bình tuyến tiền liệt $62,8 \pm 29,86 \mathrm{~mL}$, nồng độ PSA trung bình $10 \pm 18,57 \mathrm{ng} / \mathrm{mL}$. Toàn bộ các BN đều có hội chứng đường tiểu dưới mức độ nặng (IPSS > 20 điểm), trong đó chiếm tỉ lệ cao nhất là phố điểm >30 với $59,1 \%$; Tiểu rắt là triêuu chứng có tần suất lớn nhất với tỉ lệ $92,4 \%$, tiếp đến là các triệu chứng tiểu ngắt quãng $72,7 \%$ và tiểu yếu $66,7 \%$. Dạng biến đổi hình thái tuyến tiền liệt trên cộng hưởng từ thường gặp nhất theo phân loại của Wasserman là loại $1(28,8 \%)$ và loại $3(37,9 \%)$, không có trường hợp nào loại 4 . Tăng sinh lành tính tuyến tiền liệt có lôi vào lòng bàng quang chủ yếu gặp ở loại 5 với 14/23 trường hợp. Trong số các trướng hợp có lồi vào lòng bàng quang, lồi đô̂ 3 (>10mm) chiểm đa số với tỉ lệ $69,6 \%$. Kết luân: Chọn bệnh nhân can thiệp nút động mạch tuyến tiền liệt phụ thuộc nhiều yếu tố bao gồm cả triệu chứng lâm sàng và xét nghiệm sinh hóa, hình ảnh với mục đích đánh giá chính xác tình trạng bệnh. Trong đó, cộng hưởng từ là phương pháp chẩn đoán hình

${ }^{1}$ Bệnh viện Hữu Nghi

${ }^{2}$ Trung tâm Chẩn đoán hình ảnh-Bệnh viện đa khoa Tâm Anh

Chịu trách nhiệm chính: Trịnh Tú Tâm

Email: tutambvhn@gmail.com

Ngày nhận bài: 7/8/2021

Ngày phản biên khoa hoc: 7/9/2021

Ngày duyệt bài 22/9/2021
Trịnh Tú Tâm ${ }^{1}$, Nguyễn Hoàng Thịnh ${ }^{1}$, Nguyễn Quốc Dũng ${ }^{1}$, Nguyễn Xuân Hiền ${ }^{2}$

ảnh giá trị để đánh giá thể tích, hình thái, tính chất nhu mô tuyến trước can thiệp.

\section{SUMMARY}

\section{CLINICAL, PARACLINICAL AND MAGNETIC \\ RESONANCE IMAGING FEATURES $\backslash$ IN \\ PATIENTS WITH BENIGN PROSTATIC HYPERPLASIA UNDERGOING PROSTATIC ARTERY EMBOLIZATION}

Objectives: To describe the clinical, paraclinical and magnetic resonance imaging characteristics of patients with benign prostatic hyperplasia undergoing prostatic artery embolization. Subjects and research methods: A retrospective study was performed on 66 patients with benign prostatic hyperplasia who underwent prostatic artery embolectomy at Huu Nghi Hospital from May 2015 to June 2019. Describe clinical, paraclinical and magnetic resonance images before intervention. Results: From May 2015 to June 2019, there were 66 patients with mean age $73.58 \pm 7.9$ years, mean prostate volume $62.8 \pm 29.86 \mathrm{~mL}$, mean PSA concentration $10 \pm 18.57$ $\mathrm{ng} / \mathrm{mL}$. All patients had severe lower urinary tract syndrome (IPSS > 20 points), of which the highest percentage was score > 30 with 59.1\%; Urinary incontinence is the symptom with the highest frequency with the rate of $92.4 \%$, followed by the symptoms of intermittent urination $72.7 \%$ and weak urine stream $66.7 \%$. The most common form of prostate morphological change on magnetic resonance imaging according to Wasserman's classification was type $1(28.8 \%)$ and type $3(37.9 \%)$, none of which were classified as type 4 . Benign prostatic hyperplasia with protrusion into the bladder was mainly seen in type 5 with $14 / 23$ cases. Among the cases with protrusion into the bladder, grade $3(>10 \mathrm{~mm})$ accounted for the majority with the rate of $69.6 \%$. Conclusion: Selection of patients for prostatic artery embolization depends on many factors including clinical symptoms and biochemical as well as 
diagnostic imaging with the aim of accurately assessing disease status. In which, magnetic resonance is a valuable imaging method to evaluate the volume, morphology, and properties of the preinterventional parenchyma.

\section{I. ĐĂT VẤN ĐỀ}

Tăng sinh lành tính tiền liệt tuyến (TSLTTTL) là một bệnh phổ biến ở nam giới từ sau tuổi trung niên, đặc trưng bởi sự tăng sinh các tế bào biểu mô tuyến, cơ trơn và tổ chức liên kết trong vùng chuyển tiếp của tuyến tiền liệt $(T T L)$. Tỷ lệ bệnh tăng theo tuổi, có khoảng trên $50 \%$ nam giới từ 50 tuổi bị TSLTTTL, tỷ lệ này lên đến trên 90\% ở những người 80 tuổi [1]

Triệu chứng lâm sàng điển hình của TSLTTTL thường biểu hiện dưới các triệu chứng của hội chứng tăng nghẽn đường tiểu dưới gây ra bởi tình trạng tắc nghẽn cơ học do phì đại tuyến kèm theo những phản ứng thần kinh thích ứng.

Chẩn đoán TSLTTTL cần dựa vào các triệu chứng lâm sàng, xét nghiệm máu, nước tiểu và đặc biệt các phương pháp chẩn đoán hình ảnh như siểu âm, cắt lớp vi tính (CLVT), công hưởng từ $(\mathrm{CHT})$ rất có giá trị, đặc biệt là những máy CHT có từ lực manh từ 1 Tesla trở lên. CHT có thể khảo sát cả hình thái, kích thước, cấu trúc và phân vùng $T T L$, với các chuỗi xung kết hợp với tiêm thuốc đối quang có giá trị chẩn đoán rất cao trong phân biệt phì đại lành tính và ung thư TTL. Trên hình ảnh $\mathrm{CHT}$ giúp phân biệt được vùng tuyến lành và ung thư, phát hiện những khối u có kích thước nhỏ, ngoài ra có thể khảo sát di căn vùng chậu của ung thư TTL đồng thời theo dõi sau điêu trị [2].

Nút động mạch tiền liệt tuyến là phương pháp điêu trị mới, đã được chứng minh có hiệu quả và an toàn trong việc cải thiện được triệu chứng đường tiểu dưới, đồng thời làm giảm thể tích tuyến trên cả người và động vật.Kỹ thuật này đã được chấp nhận ứng dụng trong điều trị tại nhiều quốc gia trên thế giới. Mặc dù vậy việc lựa chọn đối tượng phù hợp để thực hiện kỹ thuật này hiện còn nhiều tranh cãi. Vì vậy, chúng tôi tiến hành nghiên cứu này với mục tiêu:Đánh giá một số đặc điểm lâm sàng, cận lâm sàng và hình ảnh cộng hưởng từ của bệnh nhân tăng sinh lành tính tuyến tiên liệt được can thiệp nút động mạch tuyến tiền liệt.

\section{II. ĐỐI TƯƠNG VÀ PHƯƠNG PHÁP NGHIÊN CỨU}

2.1. Đối tượng nghiên cứu. Nghiên cứu hồi cứu được thực hiện trên $66 \mathrm{BN}$ tăng sinh lành tính tiên liệt tuyển tuyến được can thiệp nút động mạch tuyến tiền liệttại BV Hữu Nghị từ 05/2015 đến 06/2019.

\subsubsection{Tiêu chuẩn lựa chọn}

- Bệnh nhân >40 tuổi

- Bệnh nhân được chẩn đoán TSLTTTL với thể tích tuyến $\geq 25 \mathrm{~mL}$

- Có điểm IPSS >18 hoặc QoL >3 hoặc cả hai

- Được chụp CHT TTL tại BV Hữu Nghị.

- Hồ sơ bệnh án, hình ảnh được lưu trữ đầy đủ

- BN được giải thích và đồng ý tham gia nghiên cứu

\subsubsection{Tiêu chuẩn loại trừ}

- Ung thư TTL (dựa trên các xét nghiệm lâm sàng, cận lâm sàng, PSA, kết quả CHT và đặc biệt là kết quả giải phẫu bệnh)

\subsection{Các bước tiến hành nghiên cứu}

- BN được khám lâm sàng để đánh giá các triệu chứng:

+ Mức độ nặng của triệu chứng lâm sàng dựa trên thang điểm IPSS

+ Mức đổ ảnh hưởng chất lượng cuộc sống được đánh giá dựa trên thang điểm QoL

- Xét nghiệm PSA được làm trước can thiệp ở tất cả các BN để sàng lọc nguy cơ ung thư

- CHT TTL được thực hiện ở tất cả các BN nghiên cứu để đo thể tích TTL, sàng lọc các tổn thương nguy cơ ác tính, phân loại kiểu hình phì đại:

+ Đánh giá các nguy cơ ác tính của các nốt tổn thương theo phân loại PIRADS 2.1

+ Đánh giá biến đổi hình thái TTL trên CHT theo phân loại của Wasserman và cs (2015), gồm 7 loại [3]:

o Loại 0: Thể tích TTL $\leq 25 \mathrm{~mL}$, không có hoặc chỉ phì đại khu trú rất ít

o Loại 1: Phì đại vùng chuyển tiếp hai bên

o Loại 2: Phì đại tuyến quanh niệu đạo (thuộc thùy trung tâm cố điển)

o Loại 3: Phì đại vùng chuyển tiếp hai bên và tuyến quanh niệu đạo

- Loại 4: Phì đại có cuống

- Loại 5: Phì đại vùng chuyển tiếp hai bên và có cuống

o Loại 6: Phì đại vùng tuyến dưới tam giác cổ bàng quang

- Loại 7: Phối hợp giữa type 6 và các nhóm ở trên

+ Đánh giá mức độ lồi vào bàng quang của $T T L$, đo bề dày phần lồi vào bàng quang của $T \mathrm{~L}$, phân làm 3 độ: độ 1 lồi $\leq 5 \mathrm{~mm}$, độ 2 lồi 5$10 \mathrm{~mm}$, độ 3 lồi >10mm.

\section{KẾT QUẢ NGHIÊN CỨU}

Qua nghiên cứu $66 \mathrm{BN}$ được chẩn đoán TSLTTTL chúng tôi thu được các kết quả sau:

Bảng 1. Đặc điểm lâm sàng và cận lâm sàng các BN trong nighiên cứu

\begin{tabular}{|l|c|l|l|}
\hline & $\begin{array}{c}\text { Trung bình } \\
\left(\mathrm{X}_{ \pm} \text {SD }\right)\end{array}$ & Min & Max \\
\hline
\end{tabular}




\begin{tabular}{|c|c|c|c|}
\hline Tuối $(n=66)$ & $73,58 \pm 7,9$ tuối & 52 & 87 \\
\hline Điếm IPSS $(n=66)$ & $30,8 \pm 2,36$ & 26 & 35 \\
\hline QoL $(n=66)$ & $4,7 \pm 0,46$ & 4 & 5 \\
\hline PSA $(n=66)$ & $10 \pm 18,57 n g / m L$ & 0,3 & 148 \\
\hline $\begin{array}{c}\text { Thế tích TTL trung } \\
\text { bình ( } n=66)\end{array}$ & $62,8 \pm 29,86 \mathrm{~mL}$ & 25 & 137 \\
\hline
\end{tabular}

- Đô tuối của các BN trong nghiên cứu tương đối cao 73,58土7,9 tuổi với BN già nhất 87 tuổi
- Toàn bộ các BN đều mắc hội chứng đường tiểu dưới mức độ nặng có ảnh hưởng rất lớn tới chất lượng cuộc sông biểu hiện ở điểm số IPSS và QoL cao

- Thể tích TTL và chỉ số PSA có khoảng thay đổi rất lớn. BN có thể tích TTL nhỏ nhất trong nghiên cứu là $25 \mathrm{~mL}$ à thể tích lớn nhất là $137 \mathrm{~mL}$.

Bảng 2. Đặc điểm triệu chứng lâm sàng đường tiểu dưới của các BN trong nghiên cứu

\begin{tabular}{|c|c|c|c|c|c|c|c|}
\hline \multirow[b]{2}{*}{ Triệu chứng } & \multirow[b]{2}{*}{$\mathbf{n}$} & \multicolumn{5}{|c|}{ Tân suất triệu chứng (tỉ lệ \%) } & \multirow[b]{2}{*}{$\begin{array}{l}\text { Tổng } \\
\text { (\%) }\end{array}$} \\
\hline & & $\begin{array}{l}\text { Có } \leq 1 / 5 \\
\text { số lần }\end{array}$ & $\begin{array}{l}\text { Có }<1 / 2 \\
\text { số lần }\end{array}$ & $\begin{array}{l}\text { Có } \approx 1 / 2 \\
\text { số lần }\end{array}$ & $\begin{array}{l}\text { Có >1/2 } \\
\text { số lần }\end{array}$ & $\begin{array}{l}\text { Thường } \\
\text { xuyênn }\end{array}$ & \\
\hline Tiếu chưa hết & 66 & 0 & 0 & 6,1 & 37,9 & 56,1 & 100 \\
\hline $\begin{array}{l}\text { Tiếu rắt (tiếu lại } \\
\text { trong vòng } 2 \text { tiếng) }\end{array}$ & 66 & 0 & 0 & 0 & 7,6 & 92,4 & 100 \\
\hline Tiểu ngắt quãng & 66 & 0 & 0 & 0 & 27,3 & 72,7 & 100 \\
\hline Tiểu gấp & 66 & 0 & 3 & 40,9 & 48,5 & 7,6 & 100 \\
\hline Tiếu yều & 66 & 0 & 0 & 0 & 33,3 & 66,7 & 100 \\
\hline Tiếu gắng sức & 66 & 0 & 7,6 & 37,9 & 51,5 & 3 & 100 \\
\hline
\end{tabular}

- Tiểu rắt là triệu chứng có tần suất lớn nhất với tỉ lệ tiểu rắt thường xuyên là $92,4 \%$, tiếp đến là các triệu chứng tiểu ngắt quãng $72,7 \%$ và tiểu yếu $66,7 \%$. Các triệu chứng tiểu gấp và tiểu gắng sức cũng gặp tần suất cao với tỉ lệ xuất hiện ở trên một nửa số lần đi tiểu là hơn $90 \%$.

Bảng 3. Phân nhóm tổng điểm triệu chứng IPSS trước điều tri

\begin{tabular}{|c|c|c|}
\hline Tống điếm IPSS & $\mathbf{n}$ & Tỉ lệ $\%$ \\
\hline$<20$ điếm & 0 & 0 \\
\hline $20-30$ điếm & 27 & 40,9 \\
\hline$>30$ điếm & 39 & 59,1 \\
\hline Tống & $\mathbf{6 6}$ & $\mathbf{1 0 0}$ \\
\hline
\end{tabular}

- Toàn bô các BN đều có hội chứng đường tiểu dưới mức độ nặng (IPSS > 20 điểm), trong đó chiếm tỉ lệ cao nhất là phổ điểm >30 với $59,1 \%$, phổ điểm từ 20-30 chiếm 40,9\%.

\begin{tabular}{|c|c|c|} 
Báng 4. Phân loại TSLTTTL trên CHT \\
\hline $\begin{array}{c}\text { Phân loại } \\
\text { Wasserman }\end{array}$ & $\begin{array}{c}\text { Số lượng BN } \\
\text { (n) }\end{array}$ & $\begin{array}{c}\text { Tỷ lệ } \\
\text { (\%) }\end{array}$ \\
\hline Loại 1 & 19 & 28,8 \\
\hline Loại 2 & 2 & 3,0 \\
\hline Loại 3 & 25 & 37,9 \\
\hline Loại 4 & 0 & 0 \\
\hline Loại 5 & 16 & 24,2 \\
\hline Loại 6 & 1 & 1,5 \\
\hline Loại 7 & 3 & 4,5 \\
\hline Tống & $\mathbf{6 6}$ & $\mathbf{1 0 0}$ \\
\hline
\end{tabular}

- Hai loại hình thái PĐLTTTL thường gặp nhất là loại 1 (phì đại vùng chuyển tiếp hai bền) với $28,8 \%$ và loại 3 (phì đại vùng chuyển tiếp hai bên và tuyến quanh niệu đạo) với $37,9 \%$. Hình thái loại 5 (phì đại vùng chuyển tiếp hai bên và có cuống) hay găp thứ ba với 24,2\%.

- Trong nghiển cứu của chúng tôi có một số trường hợp có hình thái ít gặp gồm loại 2 (2 trường hợp), loại 6 (1 trường hợp) và loại 7 (3 trường hợp) nhưng không có trường hợp nào

Bảng 5. Liên quan giữa phân loại TSLTTTL trên CHT với điểm IPSS và QoL

\begin{tabular}{|c|c|c|}
\hline $\begin{array}{c}\text { Phân loại } \\
\text { Wasserman }\end{array}$ & $\begin{array}{c}\text { IPSS trung } \\
\text { bình } \\
\left(\mathrm{X}_{ \pm} \mathbf{S D}\right)\end{array}$ & $\begin{array}{c}\text { QoL trung } \\
\text { bình } \\
\left(\mathrm{X}_{\mathbf{\pm} \text { SD }}\right)\end{array}$ \\
\hline $\begin{array}{c}\text { Loại } 1+2+3 \\
(\mathrm{n}=45)\end{array}$ & $30,5 \pm 2,39$ & $4,7 \pm 0,46$ \\
\hline $\begin{array}{c}\text { Loại } 5+6+7 \\
(\mathrm{n}=21)\end{array}$ & $31,4 \pm 2,20$ & $4,7 \pm 0,48$ \\
\hline $\begin{array}{c}\text { Kiếm định T- } \\
\text { test }\end{array}$ & $\mathrm{p}>0,05$ & $\mathrm{p}>0,05$ \\
\hline
\end{tabular}

- Không có khác biệt có ý nghĩa thống kê về điểm IPSS trung bình và QoL trung bình trước can thiệp giữa nhóm BN có hình thái TTL loại 1 , 2, 3 (không có cuống hoặc phì đại vùng sau tam giác cổ bàng quang) so với loại 5, 6, 7 (có cuống hoặc phì đại vùng sau tam giác cổ bàng quang).

Bảng 6. Phân loại TSLTTTL và múc độ lồi vào lòng bàng quang

\begin{tabular}{|c|c|c|c|c|c|}
\hline \multirow{2}{*}{\multicolumn{2}{|c|}{. }} & \multicolumn{3}{|c|}{$\begin{array}{l}\text { Mức độ lồi vào } \\
\text { lòng bàng quang }\end{array}$} & \multirow[t]{2}{*}{ Tổng } \\
\hline & & Độ 1 & Độ 2 & Độ 3 & \\
\hline \multirow{4}{*}{$\begin{array}{l}\text { Phân loại } \\
\text { PĐLTTTL } \\
\text { trên CHT }\end{array}$} & Loại 3 & 0 & 3 & 5 & 8 \\
\hline & Loại 5 & 1 & 2 & 11 & 14 \\
\hline & Loại 7 & 0 & 1 & 0 & 1 \\
\hline & T⿱ & 1 & 5 & 16 & \\
\hline
\end{tabular}

- PĐLTTTL lồi vào lòng bàng quang chủ yếu gặp ở loại 5 với 14/23

- Trong số các trường hợp có lồi vào lòng bàng quang, lồi độ 3 (>10mm) chiếm đa số với tî lệ $69,6 \%$. 


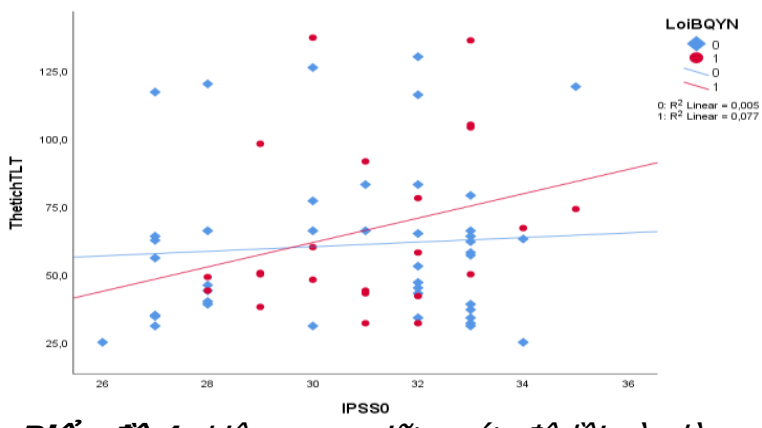

Biểu đồ 1. Liên quan giữa mức độ lồi vào lòng bàng quang, thể tích TTL và điểm điểm IPSS trước can thiêpp

- Có tương quan tuyến tính yếu giữa thể tích TTL với điểm IPSS trước can thiệp ở cả hai nhóm có lồi vào bàng quang $(n=23$, màu đỏ $)$ và nhóm không lồi vào bàng quang ( $n=43$, màu xanh), hệ số tương quan của nhóm có lồi $\left(R^{2}=0,077\right.$, rearson $=0,277$ ) cao hơn so với nhóm không lồi $\left(R^{2}=0,005\right.$, r Pearson $\left.=0,074\right)$.

- Tuy nhiên khi thực hiện kiểm định Pearson không thây mối tương quan có ý nghĩa thống kê $(p>0,05)$.

\section{BÀN LUẬN}

PĐLTTTL là bệnh tiến triển mạn tính, tỉ lệ mắc bệnh tăng dần theo lứa tuổi và gấp đôi sau mỗi 10 năm. Trong nghiên cứu của chúng tôi độ tuổi trung bình là 73,58ะ7,9 tuổi với BN cao tuổi nhất được nút mạch 87 tuổi, phần lớn $\mathrm{BN}$ nằm trong nhóm tuổi từ 70 trở lên. Kết quả này cũng tương đồng với nghiên cứu của nhiều tác giả trên thế giới [3].

Về triệu chứng lâm sàng, mặc dù hội chứng đường tiểu dưới (HCĐTD) thường liên quan tới tắc nghẽn đường ra bàng quang như là hậu quả của tình trang TSLTTTL tuy nhiên HCĐTD cũng có thể xuất hiện một mình mà không kèm theo hai tình trạng nói trên như trong trường hợp các bệnh lý nguyên phát từ bàng quang (bàng quang tăng hoạt tính, rối loạn chức năng cơ trơn bàng quang ở người cao tuổi, viêm bàng quang, rối loạn giấc ngủ). Mặt khác tình trạng tắc nghẽn đường ra bàng quang cũng có thể xuất hiện mà không có TSLTTTL hay hoàn toàn không có HCĐTD[4]. Bên cạnh đó tình trạng phì đại của TTL cũng không phải xuất hiện ở tất cả các $B N$ có HCĐTD; một số BN phì đại TTL nhưng hoàn toàn không có triệu chứng.

Thang điểm đánh giá triệu chứng tuyến tiền liệt quốc tế (IPSS) được xác định dựa trên các cẩu trả lời cho bảng cẩu hỏi được sử dụng phổ biến để sàng loc và theo dõi $B N$ PĐLTTTL và là điểm số triệu chứng được dùng phổ biến cho nút
ĐM TTL. IPSS bao gồm 7 câu hỏi liên quan đến triệu chứng và 1 câu hỏi về chất lượng cuộc sống. Tổng điểm 0-7 là bệnh nhẹ, 8-19 cho bệnh trung bình và 20-35 được coi là bệnh nặng.

Thang điểm đánh giá chất lượng cuộc sông (QoL) được sử dụng để đánh giá ảnh hưởng của triệu chứng tới cuộc sống người bệnh với tổng điểm 0-2 điểm là ảnh hưởng nhẹ, 3-4 điểm là ảnh hưởng trung bình và 5-6 điểm là ảnh hưởng nặng.

Trong nghiên cứu của chúng tôi, toàn bộ các BN đều mắc hội chứng đường tiểu dưới mức độ nặng có ảnh hưởng rất lớn tới chất lượng cuộc sống biểu hiên ở điểm số IPSS $(30,8 \pm 2,36$, min 26 , $\max 35)$ và $Q \mathrm{QL}(4,7 \pm 0,46, \min 4, \max 5)$ cao.

Trong nghiên cứu này, thể tích được đánh giá trên cộng hưởng từ, là phương pháp đo chính xác, khách quan, không phụ thuộc số lượng nước tiểu trong bàng quang. Kết quả thu được với thể tích trung bình TTL là $62,8 \pm 29,86 \mathrm{~mL}$ với khoảng thay đổi lớn từ $25 \mathrm{~mL}$ đến $137 \mathrm{~mL}$, tập trung chủ yếu trong khoảng từ $30 \mathrm{~mL}$ đến $70 \mathrm{~mL}$.

Biến đổi phì đại trong TSLTTTL chủ yếu xảy ra ở vùng trung tâm và chuyển tiếp của tuyến. Mặc dù vậy việc phân biệt giữa vùng trung tâm và vùng chuyển tiếp trên $\mathrm{CHT}$ còn nhiều tranh cãi. Nhiều tác giả cho rằng không thể phân biệt vùng trung tâm và vùng chuyển tiếp nếu chỉ dựa và tín hiệu, việc phân định chỉ mang tính tương đối dựa nhiều vào tương quan giải phẫu chúng với niệu đạo. Theo đó khái niệm thuỳ trung tâm (với ý nghĩa bao gồm cả vùng trung tâm và chuyển tiếp) được áp dụng rộng rãi trong mô tả để phản ánh hiện tượng này. Măc dù vậy môt số tác giả gần đây cho rằng có thể phân biệt được giữa vùng trung tâm và chuyển tiếp trên $\mathrm{CHT}$. Vargas và cs (2012) nghiên cứu trên nhóm BN chụp $\mathrm{CHT}$ chẩn đoán ung thư TTL cho thấy tỉ lệ có thể phân biệt được vùng trung tâm khoảng $81-84 \%$. Hansford và cS (2014) cho biết có thể phân biệt được thuỳ trung tâm ở 92-93\% BN nếu dưa trên xung $\mathrm{T} 2 \mathrm{~W}$ và $78-88 \% \mathrm{BN}$ nếu dựa trên bản đồ ADC [6].

Trong nghiên cứu của chúng tôi hình thái TSLTTTL thường gặp nhất là loại 1 (phì đại vùng chuyển tiếp hai bên) với $28,8 \%$ và loại 3 (phì đại vùng chuyển tiếp hai bên và tuyến quanh niệu đạo) với 37,9\% (Bảng 4). Hình thái loại 5 (phì đại vùng chuyển tiếp hai bên và có cuống) hay gắp thứ ba với $24,2 \%$. Ngoài ra chúng tôi còn gặp một số hình thái ít gặp gồm: loại 2 (2 trường hợp), loại 6 (1 trường hợp) và loại 7 (3 trường hợp) nhưng không gặp trường hợp nào loại 4.

Nhìn chung tình trạng phì đại của vùng chuyển tiếp trong TSLTTTL sẽ dẫn đến chèn ép 
lớp cơ ngoài của niệu đạo bên trong một vỏ xơ đệm giả và gây ra triệu chứng lâm sàng. Trong khi đó phì đại quanh niệu đạo xuất phát từ phần sâu vùng tuyến quanh cơ thắt niệu đạo. Loại phì đại này có thể dần đến tắc nghẽn đường ra của bàng quang do chèn ép bàng quang và làm dịch chuyển vùng tam giác cổ bàng quang lên phía trên. Còn dạng phì đại có cuống sẽ lồi vào lòng bàng quang gây cơ chế tắc nghẽn kiểu van đóng mở.

Trong nghiên cứu này chúng tôi nhận thấy không có khác biệt có ý nghĩa thống kê về điểm IPSS trung bình và QoL trung bình giữa nhóm $B N$ có hình thái TTL loại 1, 2, 3 (không có cuống hoặc phì đại vùng sau tam giác cổ bàng quang) so với loại 5, 6, 7 (có cuống hoặc phì đại vùng sau tam giác cổ bàng quang) (Bảng 5 ).

PĐLTTTL thường xảy ra ở vùng chuyển tiếp hai bên, dẫn đến tăng kích thước vùng chuyển tiếp, đè đẩy gây hẹp niệu đạo $T T L$, dẫn đến triệu chứng tắc nghẽn đường tiểu. Khi có biểu hiển tăng sản ở vùng trung tâm, có thể dẫn đến lî̀i vùng trung tâm vào lòng bàng quang. Trên thực hành lâm sàng, phần vùng trung tâm lồi vào lòng bàng quang được định nghĩa là khoảng cách từ vùng đỉnh của phần TTL lồi vào bàng quang đến nền bàng quang trên lát cắt đứng dọc.

Trong nghiên cứu của chúng tôi có $23 \mathrm{BN}$ TSLTTTL lồi vào lòng bàng quang. Trong số các trường hợp có lồi vào lòng bàng quang, lồi độ 3 (>10mm) chiếm đa số với tỉ lệ 69,6\% (Bảng 6). Có mối tương quan yếu giữa mức độ lồi vào lòng bàng quang với tổng điểm IPSS trong nghiên cứu của chúng tôi với chỉ số tương quan $\mathrm{R}^{2}=0,017$ và chỉ số tương quan Pearson rearson $=$ 0,131 nhưng không có ý nghĩa thống kế $(p>0,05)$.

\section{KẾT LUẬN}

Lựa chọn bệnh nhân can thiệp nút động mạch tuyến tiền liệt phụ thuộc nhiều yếu tố bao gồm cả triệu chứng lâm sàng và các xét nghiệm sinh hóa, hình ảnh với mục đích đánh giá chính xác tình trạng bệnh. Trong đó, cộng hưởng từ là phương pháp chẩn đoán hình ảnh có giá trị để đánh giá thể tích, hình thái, tính chất nhu mô tuyến trước can thiệp.

\section{TÀI LIÊU THAM KHẢO}

1. Garraway, W.M., G.N. Collins, and R.J. Lee, High prevalence of benign prostatic hypertrophy in the community. Lancet, 1991. 338(8765): p. 469-71.

2. Kirkham, A.P., et al., Prostate MRI: who, when, and how? Report from a UK consensus meeting. Clin Radiol, 2013. 68(10): p. 1016-23.

3. Wasserman, N.F., et al., Use of MRI for Lobar Classification of Benign Prostatic Hyperplasia: Potential Phenotypic Biomarkers for Research on Treatment Strategies. AJR Am J Roentgenol, 2015. 205(3): p. 564-71.

4. Dmochowski, R.R., Bladder outlet obstruction: etiology and evaluation. Rev Urol, 2005. 7 Suppl 6: p. S3-S13.

5. Shapiro, E., et al., The relative proportion of stromal and epithelial hyperplasia is related to the development of symptomatic benign prostate hyperplasia. J Urol, 1992. 147(5): p. 1293-7.

6. Hansford, B.G., et al., Dynamic contrastenhanced MR imaging features of the normal central zone of the prostate. Acad Radiol, 2014. 21(5): p. 569-77.

7. Shin, S.H., et al., Defining the degree of intravesical prostatic protrusion in association with bladder outlet obstruction. Korean J Urol, 2013. 54(6): p. 369-72.

8. Topazio, L., et al., Intravescical prostatic protrusion is a predictor of alpha blockers response: results from an observational study. BMC Urol, 2018. 18(1): p. 6.

\section{HIÊU QUẢ ĐIỀU TRI ĐAU VÙNG CỔ GÁY DO THOÁI HÓA CộT SỐNG BẰNG PHƯƠNG PHÁP CẤY CHİ KẾT HỢP CHIẾU ĐÈN TẦN PHỔ}

\section{TÓM TẮT}

Mục tiêu: Đánh giá hiệu quả điều trị đau vùng cổ gáy do thoái hóa cột sống bằng cấy chỉ kết hợp chiếu đèn tân phổ. Đối tượng và phương pháp: 60 bệnh

\footnotetext{
${ }^{1}$ Bệnh viện Châm cứu Trung ương,

${ }^{2}$ Viên Y hoc cổ truyền Quân đồi

Chịu trách nhiệm chính: Nguyễn Vinh Quốc

Email: quocnguyenvinh@gmail.com

Ngày nhận bài: 26/7/2021

Ngày phản biên khoa hoc: 25/8/2021

Ngày duyệt bài: 18/9/2021
}

\section{Nguyễn Đức Minh ${ }^{1}$, Nguyễn Vinh Quốc ${ }^{2}$}

nhân tuổi trên 30 được chẩn đoán đau vùng cổ gáy do thoái hóa cột sống, không phân biệt giới tính, nghề nghiêp, tình nguyênn tham gia nghiển cứu. Nhóm đối chứngđiều trị bằng xoa bóp bấm huyệt kết hợpchiếu đèn tần phổ, nhóm nghiên cứu điều trị như nhóm đối chứng kết hợp cấy chỉ. So sánh kết quả sau 20 ngày điều trị. Kết quả: Cấy chỉ kết hợp chiếu đèn tần phổhiệu quả trong điêu trị đau vùng cổ gáy do thoái hóa cột sống, $90 \%$ đạt hiệu quả tốt và khá. Biên độ hoat động cột sống cổ, mức độ đau và mức độ hạn chể sinh hoạt hàng ngày NDI cải thiện tốt hơn có ý nghĩa so với trước điều trị và tốt hơn so với nhóm đối chứng. Kết luận: Cấy chỉ kết hợp chiếu đèn tần 